Article

\title{
Evaluation of RNA Interference for Control of the Grape Mealybug Pseudococcus maritimus (Hemiptera: Pseudococcidae)
}

\author{
Arinder K. Arora ${ }^{1}$, Noah Clark ${ }^{1}$, Karen S. Wentworth ${ }^{2}$, Stephen Hesler ${ }^{2}$, Marc Fuchs ${ }^{3}{ }^{(D)}$, \\ Greg Loeb ${ }^{2}(\mathbb{D})$ and Angela E. Douglas ${ }^{1,4, *}$ \\ 1 Department of Entomology, Cornell University, Ithaca, NY 14850, USA; aka76@cornell.edu (A.K.A.); \\ clark.noah@gmail.com (N.C.) \\ 2 Department of Entomology, Cornell University, Geneva, NY 14456, USA; ksw2@cornell.edu (K.S.W.); \\ sph12@cornell.edu (S.H.); gme1@cornell.edu (G.L.) \\ 3 School of Integrative Plant Science, Cornell University, Geneva, NY 14456, USA; marc.fuchs@cornell.edu \\ 4 Department of Molecular Biology and Genetics, Cornell University, Ithaca, NY 14853, USA \\ * Correspondence: aes326@cornell.edu
}

Received: 19 September 2020; Accepted: 26 October 2020; Published: 28 October 2020

check for updates

Simple Summary: RNA interference (RNAi) is a defense mechanism that protects insects from viruses by targeting and degrading RNA. This feature has been exploited to reduce the expression of endogenous RNA for determining functions of various genes and for killing insect pests by targeting genes that are vital for insect survival. When dsRNA matching perfectly to the target RNA is administered, the RNAi machinery dices the dsRNA into 21 bp fragments (known as siRNAs) and one strand of siRNA is employed by the RNAi machinery to target and degrade the target RNA. In this study we used a cocktail of dsRNAs targeting grape mealybug's aquaporin and sucrase genes to kill the insect. Aquaporins and sucrases are important genes enabling these insects to maintain water relations indispensable for survival and digest complex sugars in the diet of plant sap-feeding insects, including mealybugs. In our experiments, administration of dsRNA caused a reduction in expression of the target genes and an increase in insect mortality. These results provide support for the application of RNAi to control the grape mealybug.

Abstract: The grape mealybug Pseudococcus maritimus (Ehrhorn, 1900) (Hemiptera: Pseudococcidae)
is a significant pest of grapevines (Vitis spp.) and a vector of disease-causing grape viruses, linked to
its feeding on phloem sap. The management of this pest is constrained by the lack of naturally
occurring resistance traits in Vitis. Here, we obtained proof of concept that RNA interference (RNAi)
using double-stranded RNA (dsRNA) molecules against essential genes for phloem sap feeding can
depress insect survival. The genes of interest code for an aquaporin (AQP) and a sucrase (SUC)
that are required for osmoregulation in related phloem sap-feeding hemipteran insects (aphids and
whiteflies). In parallel, we investigated the grape mealybug genes coding non-specific nucleases
(NUC), which reduce RNAi efficacy by degrading administered dsRNA. Homologs of $A Q P$ and $S U C$
with experimentally validated function in aphids, together with NUC, were identified in the published
transcriptome of the citrus mealybug Planococcus citri by phylogenetic analysis, and sequences of the
candidate genes were obtained for Ps. maritimus by PCR with degenerate primers. Using this first
sequence information for Ps. maritimus, dsRNA was prepared and administered to the insects via an
artificial diet. The treatment comprising dsRNA against $A Q P, S U C$ and NUC significantly increased
insect mortality over three days, relative to dsRNA-free controls. The dsRNA constructs for $A Q P$ and
NUC were predicted, from sequence analysis to have some activity against other mealybugs, but none
of the three dsRNA constructs have predicted activity against aphids. This study provides the basis
to develop in planta RNAi strategies against Ps. maritimus and other mealybug pests of grapevines. 
Keywords: grapevine pests; mealybugs; osmoregulation genes; phloem-feeding insects; Pseudococcus maritimus; RNA interference

\section{Introduction}

The grape mealybug, Pseudococcus maritimus (Ehrhorn, 1900), is a polyphagous insect that feeds through its life cycle on plant phloem sap. It has a broad geographical distribution in Eurasia and North America, and, throughout its range, it is a pest of deciduous fruit crops, including apple, pear and grape [1]. In particular, Ps. maritimus reduces the vigor of grape plants by direct feeding damage, the deposition of honeydew and by transmission of grapevine leafroll-associated viruses (GLRaVs), reducing grape yield by up to $70 \%$ [2-4].

Ps. maritimus can be controlled by systemic insecticides [5]. It is unclear, however, whether conventional insecticidal control, on its own, is sufficiently effective to reduce the spread of GLRaVs [4]. Therefore, this pest is an important target for the development of alternative control strategies. A promising candidate approach is RNA interference (RNAi)-mediated suppression of the expression of essential insect genes, which can be targeted specifically to the pest species with no deleterious effects on other organisms, including beneficial insects and the human consumer [6-9]. This specificity arises from the molecular mechanism of RNAi [10,11]. Briefly, double-stranded RNA (dsRNA) is internalized into cells, where it is cut by an enzyme, Dicer, into $21 \mathrm{bp}$ fragments known as small interfering RNA duplex (siRNA duplex). The siRNA duplex is then loaded onto the multi-subunit RNA-induced Silencing Complex (RISC) complex, one strand of the siRNA is selected and any mRNA with complementary sequence is degraded by the enzyme Argonaute. The dsRNA can be delivered to insects by feeding, either as a food supplement or, for phytophagous insects, by genetic modification of the plant [12-14]. Transcriptome data [15,16] demonstrate that RNAi is active in the citrus mealybug Planococcus citri (Risso, 1900) (Hemiptera: Pseudococcidae) and the cotton mealybug Phenacoccus solenopsis (Tinsley, 1898) (Hemiptera: Pseudococcidae), and RNAi has been successfully applied to these two species [17-19].

The basis for our strategy to develop RNAi as a control strategy against Ps. maritimus was the prior research on RNAi against other phloem-feeding hemipteran insects of the suborder Sternorrhyncha. Sternorrhyncha comprises the Coccoidea (scale insects and mealybugs), Aleyrodoidea (whiteflies), Psylloidea (psyllids) and Aphidomorpha (aphids and phylloxerids). Our specific focus is the genes encoding aquaporin water channel $(A Q P)$ and sucrase (SUC), which are overly expressed in the gut and their translated proteins mediate the osmoregulatory control of body fluids of these insects [20-22]. Specifically, the sugar-rich diet of phloem sap exerts a high osmotic pressure that, on ingestion into the gut, is predicted to draw water from the insect body fluids to the gut lumen. The loss of body water leads to insect desiccation and death [23-25]. Osmotic collapse is prevented by two enzymatic activities of the sucrase; first, sucrase-mediated hydrolysis of ingested sucrose and, second, transglucosidation of the released glucose to form oligosaccharides, thereby reducing the osmotic pressure, together with aquaporin-facilitated water cycling between the distal and proximal gut regions [26]. AQP and SUC have been validated experimentally in the pea aphid Acyrthosiphon pisum (Harris, 1776) (Hemiptera: Aphididae) [21,22] and AQP in the whitefly Bemisia tabaci (Gennadius, 1889) (Hemiptera: Aleyrodidae) [20,27]. Furthermore, RNAi knockdown of the expression of one or both $A Q P$ and SUC increases mortality in the aphid Myzus persicae (Sulzer, 1776) (Hemiptera: Aphididae), the whitefly Bemisia tabaci, the mealybug Ph. solenopsis and the psyllid Diaphorina citri (Kuwayama, 1908) (Hemiptera: Liviidae) [16,28-31]. We reasoned that this technology would be applicable to Ps. maritimus, following phylogenetic evidence that the citrus mealybug $P l$. citri has genes homologous to the osmoregulatory $A Q P$ and SUC in aphids and whiteflies [32].

The goal of this study was to obtain proof of principle that RNAi can be applied against Ps. maritimus. This required us to address three challenges. The first was to develop a reliable protocol for laboratory 
culture of the insect for experimental study, and a feeding protocol for dsRNA delivery. The second was to obtain $A Q P$ and SUC sequences for dsRNA synthesis. No published sequence data for this species are available, and our strategy was to sequence PCR amplicons generated from Ps. maritimus cDNA with degenerate primers designed from homologous genes in other insects. The final challenge arose from the well-documented variability in RNAi efficacy against phloem-feeding insects and other insects [7,33-35]. Focusing on RNAi against osmoregulation genes in phloem-feeding insects, research on aphids and whiteflies has revealed that RNAi efficacy is markedly improved by supplementing the administered ds $A Q P$ and dsSUC with RNAi against the gene coding a gut nuclease (NUC) that mediates the nonspecific degradation of ingested dsRNA [28,36,37]. The dsRNA-degrading activity has also been reported in the mealybug Ph. solenopsis, together with evidence that dsRNA against the nuclease sequence improves RNAi efficacy, but the repertoire of candidate NUC in mealybugs has not been explored systematically [16]. Anticipating that nuclease activity may impair RNAi against Ps. maritimus, our molecular analysis of this species was extended to identify NUC sequences, and then to co-administer the dsRNA against $A Q P$, SUC and NUC to the insects. This study reports the development of specific RNAi molecules for a pest species that lacked prior molecular information, and it provides the first evidence for RNAi against osmoregulation genes as a potential control approach against $P$ s. maritimus.

\section{Materials and Methods}

\subsection{Insects}

Grape mealybugs Ps. maritimus were collected from a vineyard ( $V$. vinifera cultivar Chardonnay) in Seneca County, Finger Lakes region of NY $\left(42^{\circ} 41^{\prime} 05.38^{\prime \prime} \mathrm{N}\right.$ and $\left.76^{\circ} 44^{\prime} 37.52^{\prime \prime} \mathrm{W}\right)$ on 19 and $25 \mathrm{July}$ and 2 August 2018, and combined to generate a laboratory culture on V. vinifera cv. "Pixie" [38]. The culture was maintained at $21^{\circ} \mathrm{C}$ with $17 \mathrm{~h}$ light: $7 \mathrm{~h}$ dark. Frozen vine mealybugs $\mathrm{Pl}$. ficus were provided by Dr. Kent Daane from a culture at The Kearney Agricultural Research and Extension Center, Parlier, CA, derived from collections in Fresno County, CA.

\subsection{RNA Extraction}

For each gut sample, 30-35 insects were dissected in diethyl pyrocarbonate (DEPC)-treated phosphate-buffered saline (PBS), $\mathrm{pH} 7.4$, using fine pins under a dissecting microscope at 1.5-2X magnification. The isolated guts were immediately transferred to $50 \mu \mathrm{L}$ RNAlater (Thermo Fisher, Waltham, MA, USA), stored at $4{ }^{\circ} \mathrm{C}$ overnight, and then at $-20{ }^{\circ} \mathrm{C}$. Immediately prior to RNA extraction, $75 \mu \mathrm{L}$ DEPC-treated PBS were added to each thawed tube, mixed gently by inverting 10 times, and centrifuged at $5000 \mathrm{~g}$ for $5 \mathrm{~min}$. The supernatant was removed.

Each sample of whole bodies or pelleted guts of Ps. maritimus, and each whole body sample of Pl. ficus was mixed with $200 \mu \mathrm{L}$ or $50 \mu \mathrm{L}$ RNAzol (catalog \# R4533, Millipore Sigma, Burlington, MA, USA), respectively, and then homogenized using a plastic pestle. An additional $150 \mu \mathrm{L}$ RNAzol was added to the gut homogenates, which were then vortexed. Total RNA was extracted following the manufacturer's RNAzol RT protocol. The RNA was precipitated with an equal amount of cold isopropanol and $1 \mu \mathrm{L}$ linear acrylamide. Following incubation, for $10 \mathrm{~min}$ at room temperature (whole bodies) or overnight at $-20^{\circ} \mathrm{C}$ (guts), the samples were centrifuged at $12,000 \times g$ for 10 min at $4{ }^{\circ} \mathrm{C}$. The pellet was washed twice with ice-cold $75 \%$ ethanol and resuspended in $15 \mu \mathrm{L}$ nuclease-free water.

\subsection{Design of Primers for Amplification of Ps. maritimus and Pl. ficus Genes}

The published phylogenetic trees for the three genes of interest, AQP1, SUC1 (32) and NUC1 (28) in sternorrhynchan Hemiptera were updated with additional sequence data recently published in NCBI, including sequences of the mealybug Pl. citri, as described in Text S1 and displayed in Figures S1-S3. In parallel, sequences were collated for the $\beta$-tubulin gene (Figure S4) used as a normalizing gene for quantitative PCR. The sequences for each gene were aligned using the multiple sequence alignment 
tool MUSCLE [39] (www.ebi.ac.uk/Tools/msa/muscle/), in conjunction with the Base-by-Base editor (4virology.net/virology-ca-tools/base-by-base), to identify conserved sequences. Degenerate primers were then designed using Primaclade (http://primaclade.org/cgi-bin/primaclade.cgi) (Table S1A).

\section{4. cDNA Synthesis and Sequencing}

First-strand cDNA was synthesized using a Superscript II Reverse Transcriptase Kit (Catalog \# 18064014, ThermoFisher Scientific, Waltham, MA, USA) and 100 ng RNA from whole bodies of Ps. maritimus or Pl. ficus, following the manufacturer's instructions. The cDNA was then used as a template for amplification of the predicted orthologs of AQP1, SUC1 and NUC1, using $12.5 \mu \mathrm{L}$ GoTaq Green Master Mix (Catalog \# M7122, Promega, Madison, WI, USA), $0.625 \mu \mathrm{M}$ of each primer (Supplemental Table S1A), $1 \mu \mathrm{L}$ cDNA template and $9 \mu \mathrm{L}$ water. The PCR reaction conditions were optimized for each gene (Supplemental Table S2). The PCR products were purified using a QIAquick PCR Purification Kit (Catalog \# 28104, Qiagen, Hilden, Germany) following the manufacturer's instructions and checked for predicted length by gel electrophoresis, prior to Sanger sequencing. The sequences are available at NCBI as accession numbers MT187985, MT187986, MT187988, MT187989, MT192030, MT192031 and MT192032.

\subsection{Quantitative Real-Time PCR ( $q$ RT-PCR)}

Gene expression was quantified by qRT-PCR that comprised $5 \mu$ iQ SYBR Green supermix (Catalog\# 1708862, BioRad, Hercules, CA), $0.5 \mu$ primers, each at $10 \mu \mathrm{M}$ (Table S1B), $1 \mu \mathrm{L}$ cDNA and $3 \mu \mathrm{L}$ water. The reactions were run in a C100 Thermal Cycler with a CFX96 Touch ${ }^{\mathrm{TM}}$ Real-Time PCR Detection System (Bio-Rad) at $95^{\circ} \mathrm{C}$ for $3 \mathrm{~min}, 95^{\circ} \mathrm{C}$ for $10 \mathrm{~s}$, followed by annealing and extension at $60{ }^{\circ} \mathrm{C}$ for $30 \mathrm{~s}$ for 40 cycles. A dissociation curve included in each assay comprised $65^{\circ} \mathrm{C}$ to $95^{\circ} \mathrm{C}$ (minimum to maximum temperatures) in $0.5^{\circ} \mathrm{C}$ increments per $0.05 \mathrm{~s}$, yielding single gene-specific peaks. All experiments included Ps. maritimus $\beta$-tubulin (accession number MT187989) as a normalizing gene and template-free samples as negative controls. The mean $C t$ values for two technical replicates were calculated, and the difference between experimental and control samples was determined as the $\log _{2}$ fold difference [40].

\subsection{Synthesis of dsRNA}

A target sequence for each gene was identified using SOL Genomics Network VIGStool (www. solgenomics.net) with no predicted non-target activity against Vitis vinifera. Each sequence-ds $A Q P 1$ (250 bp), dsSUC1 (240 bp) and dsNUC1 (250 bp)—was amplified from Ps. maritimus cDNA (primers provided in Table S1C), cloned in pGEMT Easy plasmid (Catalog \# A1360, Promega, Madison, WI, USA), and transformed into Escherichia coli DH5 $\alpha$ (Catalog \# 18258012, ThermoFisher Scientific), following the manufacturer's protocol. The cloned gene was sequenced to confirm the sequence. The plasmid was purified using a Zymo PURE Plasmid Miniprep Kit (Catalog \# D4209, Zymo Research, Irvine, CA, USA), and the target sequence was confirmed by Sanger sequencing. The target sequence was amplified and used as a template for dsRNA synthesis by an AmpliScribe T7-Flash Transcription Kit (Catalog \# ASF3507, Lucigen, Middleton, WI, USA), and purified following the manufacturer's instructions. The size of synthesized dsRNA was confirmed by gel electrophoresis, and dsRNA concentration was measured using a NanoDrop photometer. In parallel, a plasmid pGFP2 containing a $370 \mathrm{bp}$ long green fluorescent protein (GFP) DNA template [28] was used to synthesize dsRNA of GFP.

\subsection{RNAi Experiments}

dsRNA was delivered orally to ca. 30-day-old (2nd-3rd instar) Ps. maritimus mealybugs, using a sachet of $100 \mu \mathrm{L}$ sterile artificial liquid diet sandwiched between two layers of Parafilm. The method followed the procedure previously developed for aphids [41], with two modifications (Figure 1). First, the Parafilm diet sachet was not stretched taut, following observations that mealybugs preferentially feed at the wrinkles in the Parafilm. Second, the base of the cage was sealed with a single sheet 
of Parafilm, after the addition of the insects to the cage, to prevent escape. Each 5-day experiment comprised a single replicate cage for five treatments, and the experiment was repeated four times over four consecutive weeks. The experimental design comprised a 2-day pre-treatment and a 3-day treatment (Table 1). The pre-treatment diets were supplemented or not with dsNUC1. For the treatment phase of the experiment, the test diets contained dsAQP1 and dsSUC1, either with or without dsNUC1 (treatments $\mathrm{A}+\mathrm{S}$ and $\mathrm{N}+\mathrm{A}+\mathrm{S}$, respectively). As controls for non-specific effects of dsRNA, replicated sets of insects were fed with dsGFP (treatment G) or dsGFP and dsNUC1 (treatment N+G), and the experiments also included dsRNA-free diet (treatment Diet). The dsNUC1 was delivered at $0.2 \mu \mathrm{g} \mu \mathrm{L}^{-1}$, and the total dsRNA concentration was $0.4 \mu \mathrm{g} \mu \mathrm{L}^{-1}$ in all treatments at day 2 to day 5 (see Table 1 for details). On day 5 of the experiment (Table 1), the surviving insects were counted, and the guts were dissected and stored in RNAlater for RNA extraction and quantification of gene expression by qRT-PCR.

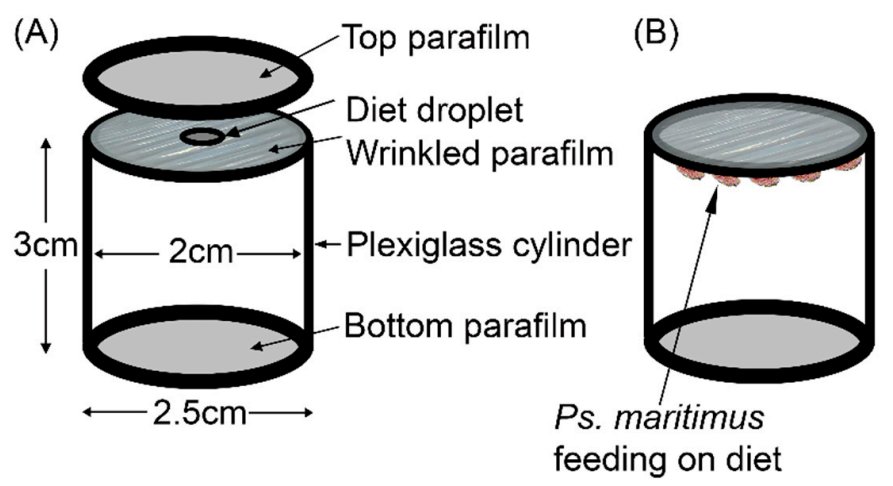

Figure 1. Rearing Pseudococcus maritimus on an artificial liquid diet. (A) The components of the diet cage, with diet sachet at the top. (B) An assembled diet cage with feeding P. maritimus.

Table 1. Experimental design for RNA interference (RNAi) experiments.

\begin{tabular}{ccc}
\hline \multirow{2}{*}{ Treatment } & \multicolumn{2}{c}{ Double Stranded RNA (dsRNA) in Diet } \\
\cline { 2 - 3 } & Day 0 to Day 2 Larvae & Day 2 to Day 7 Larvae \\
\hline Diet & dsRNA free & dsRNA free \\
G & dsRNA free & dsGFP $\left(0.4 \mu \mathrm{g} \mu \mathrm{L}^{-1}\right)$ \\
$\mathrm{N}+\mathrm{G}$ & $\mathrm{dsNUC1}\left(0.2 \mu \mathrm{g} \mu \mathrm{L}^{-1}\right)$ & $\mathrm{ds} G F P\left(0.2 \mu \mathrm{g} \mu \mathrm{L}^{-1}\right)+\mathrm{dsNUC1}\left(0.2 \mu \mathrm{g} \mu \mathrm{L}^{-1}\right)$ \\
$\mathrm{A}+\mathrm{S}$ & $\mathrm{dsRNA}$ free & $\mathrm{ds} A Q P 1\left(0.2 \mu \mathrm{g} \mu \mathrm{L}^{-1}\right)+\mathrm{ds} S U C 1\left(0.2 \mu \mathrm{g} \mu \mathrm{L}^{-1}\right)$ \\
$\mathrm{N}+\mathrm{A}+\mathrm{S}$ & $\mathrm{dsNUC1}\left(0.2 \mu \mathrm{g} \mu \mathrm{L}^{-1}\right)$ & $\mathrm{ds} A Q P 1\left(0.1 \mu \mathrm{g} \mu \mathrm{L}^{-1}\right)+\mathrm{dsSUC1}\left(0.1 \mu \mathrm{g} \mu \mathrm{L}^{-1}\right)+$ \\
& & $\mathrm{dsNUC1}\left(0.2 \mu \mathrm{g} \mu \mathrm{L}^{-1}\right)$ \\
\hline
\end{tabular}

\subsection{Species Specificity of dsRNA Reagents}

The predicted activity of dsRNA sequences designed for Ps. maritimus against Pl. citri and Pl. ficus was investigated using siRNA-Finder (si-Fi) software (https://github.com/snowformatics/siFi21) [42], using default settings with $21 \mathrm{bp}$ siRNA and zero mismatch. The cDNA sequences of $A Q P 1, N U C 1$ and SUC1 of non-target species were added in si-Fi as the database and dsRNA sequences of $A Q P 1$, NUC1 and SUC1 from Ps. maritimus were used as a query to find the numbers of $21 \mathrm{bp}$ segments that matched perfectly.

\subsection{Statistical Analysis}

The data were analyzed using $\mathrm{R}$ software version 3.5.1 [43]. To analyze mealybug survival, a generalized linear model with a logit link was performed using the "glmer" function from the lme4 package version 1.1-2.1, with dsRNA treatments as categorical fixed effects and experiment as a random effect $[43,44]$. The $\log _{2}$ fold differences in gene expression were analyzed as a linear model using the "lm" function, with treatments as categorical predictors. To test for differences in mealybug 
survival and gene expression between insects on the dsGFP diet (treatment G in Table 1) and other treatments, the regression coefficient for each treatment was calculated using the coefficient regression $t$-test in the "glmer" and "lm" functions with treatment G set as the reference.

\section{Results}

\subsection{Identification of Target Genes in Pseudococcus maritimus and Design of dsRNA Sequences}

At the start of this study, no sequence information was available for the mealybug Ps. maritimus, but a single ortholog of the osmoregulation genes of the pea aphid (ApAQP1 and ApSUC1) had been identified in the transcriptome of a different mealybug species, Planococcus citri [32]. Our first analysis made use of recently published sequence data to update the phylogeny of $A Q P$ genes and glycoside hydrolase family 13 (including ApSUC1) genes in the sternorrhynchan hemipterans (Figures S1A,B and $\mathrm{S} 2 \mathrm{~A}, \mathrm{~B})$. The consensus Bayesian and maximum likelihood (ML) trees confirmed the single orthologs of $A p A Q P 1$ and ApSUC1 in Pl. citri, and we named these orthologs PcAQP1 and PcSUC1, respectively. Applying the same approach, we investigated homolog(s) of the pea aphid nuclease (ApNUC1), which mediates the nonspecific degradation of orally delivered dsRNA [37]. The Bayesian and ML analyses (Figure S3A,B) identified a single ortholog in Pl. citri, which we named PcNUC1.

We then designed degenerate primers to regions of $A Q P 1, S U C 1$ and NUC1 that were predicted not to amplify other aquaporin, GH-13 or nuclease genes, based on the gene sequences of the mealybug Pl. citri, the aphids A. pisum and M. persicae and the whitefly B. tabaci (Figures S1C, S2C and S3C; Table S1A). With these primers and end-point PCR reactions, we amplified orthologous genes from cDNA of our focal mealybug species, Ps. maritimus. Sanger sequencing of the PCR products yielded single sequences that had high sequence similarity to PCAQP1, PCSUC1 and PcNUC1 and that, on translation, generated the predicted protein domains using the NCBI conserved domain database (https://www.ncbi.nlm.nih.gov/cdd/). The Ps. maritimus sequences are available in NCBI as accession numbers MT187985, MT187986 and MT187988, respectively.

Finally, we designed dsRNA sequences against each of the three Ps. maritimus genes of interest and cloned them as described in the Material and Methods. Because dsRNA can potentially be used to develop pest control strategies, we tested the predicted non-target potential of the dsRNAs against homologous gene sequences of insects other than Ps. maritimus (Table 2). Our results revealed that $d s A Q P 1$ and dsNUC1 have limited predicted non-target potential to other mealybug species of the same family (detailed in Figure S5), and no predicted non-target potential against species in the sister group, the aphids; dsSUC1 has no predicted potential against either mealybug or aphid species.

Table 2. Predicted species specificity of Pseudococcus maritimus dsRNA sequences, determined using si-Fi software. The Planococcus species are members of the same family (Pseudococcidae) of Coccoidea as Ps. maritimus, and A. pisum and M. persicae are aphids (superfamily Aphidoidea, sister taxon to superfamily Coccoidea).

\begin{tabular}{ccc}
\hline $\begin{array}{c}\text { dsRNA Sequence of } \\
\text { Ps. maritimus }\end{array}$ & Insect Species & $\begin{array}{c}\text { Number of Predicted Targets of dsRNA-Derived } \\
\text { 21 nt Predicted Target Sequences }\end{array}$ \\
\hline dsAQP1 & Planococcus citri & 27 \\
& Planococcus ficus & 17 \\
& Acyrthosiphon pisum & 0 \\
dsSUC1 & Myzus persicae & 0 \\
& Planococcus citri & 0 \\
& Planococcus ficus & 0 \\
& Acyrthosiphon pisum & 0 \\
dsNUC1 & Myzus persicae & 0 \\
& Planococcus citri & 9 \\
& Planococcus ficus & 1 \\
& Acyrthosiphon pisum & 0 \\
& Myzus persicae & 0 \\
\hline
\end{tabular}




\subsection{Expression of Target Genes in the Gut of Ps. maritimus}

We quantified the expression of the target genes PmAQP1, PmSUC1 and PmNuc1 in dissected guts, compared to whole bodies, for three separate collections from the laboratory colony of Ps. maritimus (Figure 2). Transcripts of all three genes were significantly more abundant in the gut samples, and the mean enrichment was 20-fold, 66-fold and 17-fold, respectively. These results are consistent with their putative function in the gut and their suitability for targeting via orally delivered RNAi.
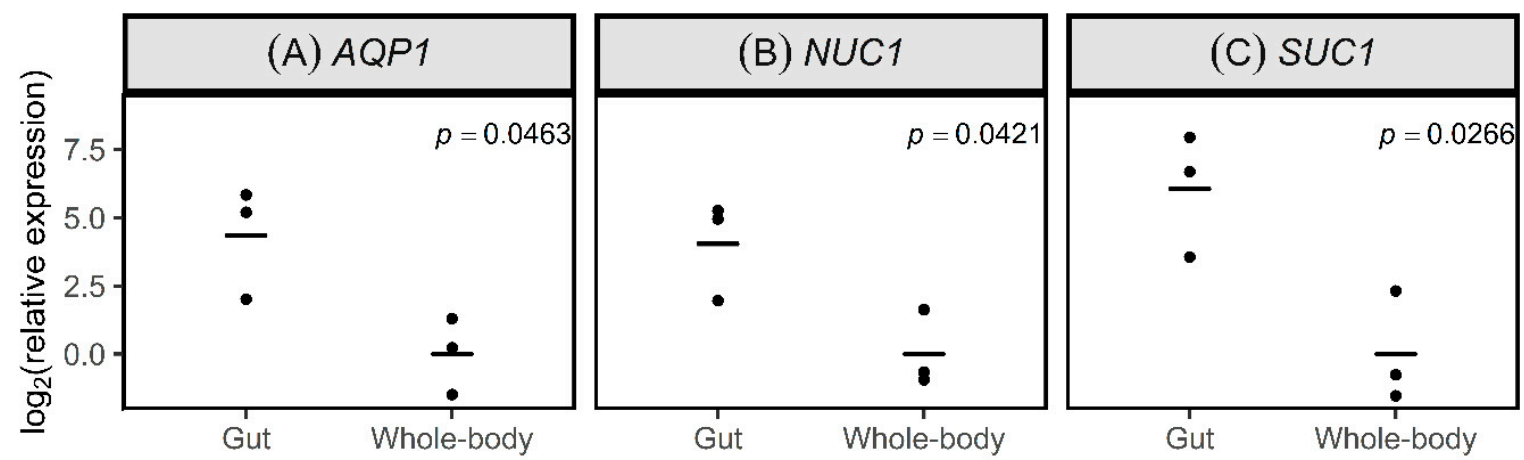

Figure 2. Expression of genes in the gut and whole body of 2nd-3rd instar nymphs of Pseudococcus maritimus. The mean values are shown as horizontal bars. Target genes are (A) AQP1, (B) NUC1 and (C) SUC1. Three biological replicates, each comprising 30-35 guts and 10-15 whole bodies were used. The data were analyzed by $t$-test, and p-values are provided.

\subsection{Response of Ps. maritimus to Orally Delivered RNAi}

In preliminary experiments, we administered dsRNA to the mealybugs by two complementary methods. The first was the petiole dip assay, i.e., the petiole of a freshly cut grape leaf bearing feeding mealybugs was immersed in a solution of dsRNA [16]. However, the insects failed to settle and feed on the excised leaves, whether the petiole was immersed in deionized water or dsRNA preparations. This method was not pursued further. Our second approach used membrane feeding with an artificial liquid diet sandwiched between two layers of Parafilm. The mealybugs settled and fed from the artificial diet, especially favoring the edges of folds that we mechanically introduced to the Parafilm membrane (Figure 1). The insects could be maintained on the artificial diet for up to one week with low mortality. Long-term culture of Ps. maritimus on the artificial diet was not attempted because transfers to a fresh diet without damaging the insects was inordinately time-consuming. Based on our preliminary trials, we devised a 5-day experimental protocol (Table 1) using mealybugs administered dsRNA via the artificial diet. On the dsRNA-free diet ('Diet' in Table 1), 80\% of the mealybugs survived the 3-day treatment (Figure 3 and Dataset S1). Survival varied significantly across the five treatments. Compared to treatment G (dsRNA against GFP), the linear model yielded a statistically significant reduction in survival of treatment $\mathrm{N}+\mathrm{A}+\mathrm{S}$ (dsRNA against $P m A Q P 1, P m S U C 1$ and $P m N U C 1$ ) (Figure 3 with statistical analysis in Table S3, $p<0.1$ ). The non-significant effect of dsAQP1 and dsSUC1 without dsNUC1 (treatment $\mathrm{A}+\mathrm{S}$ ) suggested that dsRNA against the nuclease gene promotes the efficacy of dsRNA against PmAQP1 and PmSUC1, as previously demonstrated for aphids [37] and whiteflies [28].

We also quantified expression of PmAQP1, PmSUC1 and PmNUC1 in the guts dissected from insects that survived the 5-day experiment. Expression of all three genes varied significantly with treatment, and transcript abundance was significantly reduced in insects from treatment $\mathrm{N}+\mathrm{A}+\mathrm{S}$ relative to the GFP-dsRNA treatment (treatment G) (Figure 4 with statistical analysis in Table S4, $p<0.1$. The data fitted to the expectation that dsRNA against PmAQP1 and PmSUC1 would result in reduced expression of these genes, respectively. However, PmNUC1 expression was, similarly, expected to be reduced to an equivalent extent in the treatments that included dsNUC1 (treatments $\mathrm{N}+\mathrm{G}$ and $\mathrm{N}+\mathrm{A}+\mathrm{S}$ ), but this result was not obtained. We discuss possible reasons for these results in the discussion. 


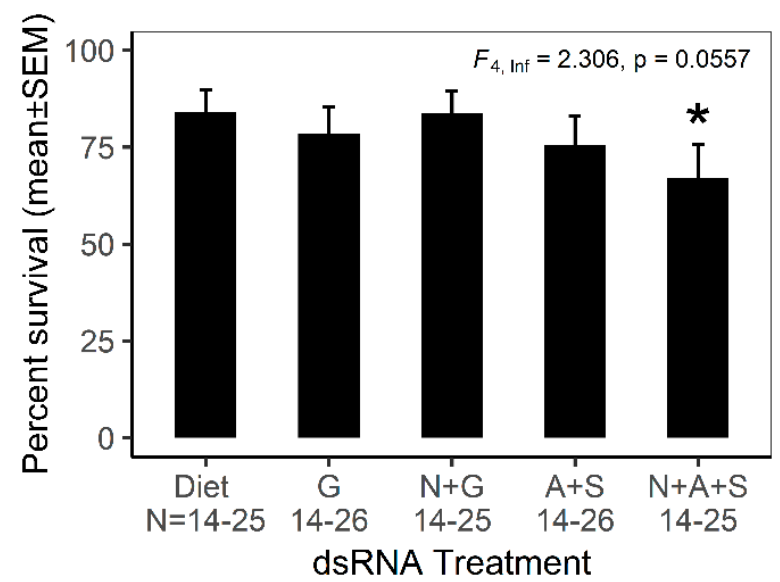

Figure 3. Impact of RNAi on survival of Ps. maritimus over 5 days. GLMER test with critical probability of 0.1 was applied to compare each treatment to the dsRNA-free diet control, and significantly different treatment is indicated by asterisk (results from statistical analysis are provided in Table S3). The experiment was conducted four times, each time with a single diet cage per treatment. The range of the number of insects per replicate for each treatment $(\mathrm{N})$ is shown on the $x$-axis. The acronyms for treatments are: A, dsAQP1; G, dsGFP; , dsNUC1; S, dsSUC1 (see Table 1).
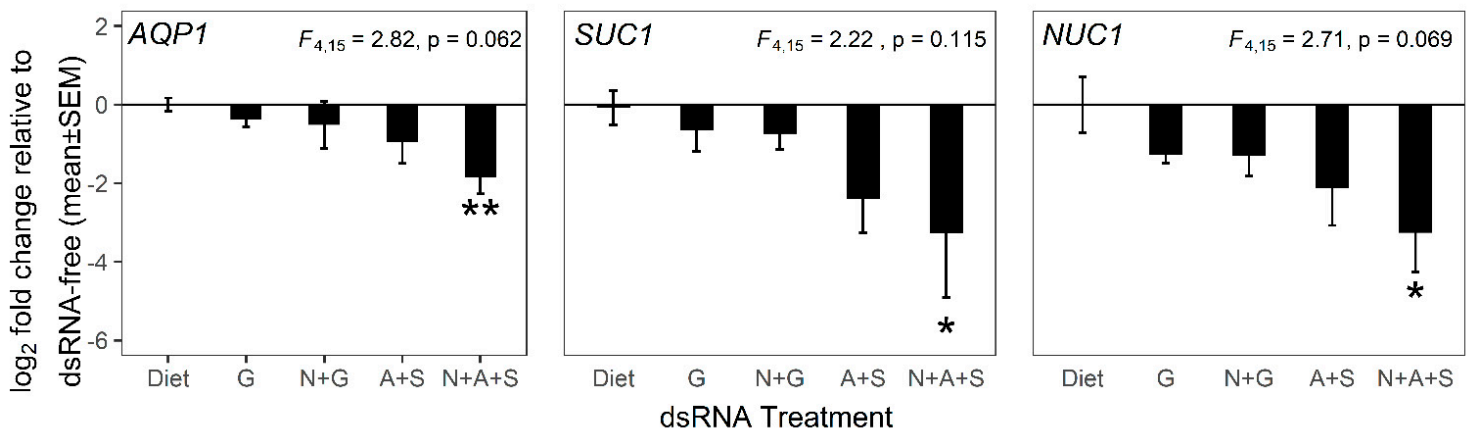

Figure 4. Impact of RNAi on expression of targeted Ps. maritimus genes AQP1 (left panel), SUC1 (middle panel) and NUC1 (right panel). Linear model statistics were calculated and all the treatments were compared to dsRNA-free diet control. The double and single asterisks depict significant differences from dsRNA-free diet at $\alpha=0.05$ and 0.1 , respectively (results from statistical analysis are provided in Table S4). The experimental details and treatment description are as in Figure 3. The range of number of insects used in each treatment are: Diet, 12-21; G, 10-18; N+G, 10-20; A+S, 9-19; N+A+S, 9-17.

\section{Discussion}

In this study, we obtained evidence that orally administered RNAi against osmoregulation genes causes a significant increase in mortality of the grape mealybug Ps. maritimus over a three-day period.

The rationale for this study arose from the generality that homologous $A Q P$ and SUC genes mediate osmoregulation in the gut of different phloem-feeding sternorrhynchan Hemiptera. This generated the expectation that candidate gene targets for a previously unstudied species can be identified by phylogenetic analysis of the aquaporin gene family and glucosyl hydrolase-13 (GH-13) gene family, respectively $[27,32]$. Consistent with this expectation, the candidate Ps. maritimus genes that we identified from phylogenetic analysis displayed the predicted features of osmoregulation genes: enriched expression in the gut and increased mortality of insects administered dsRNA specific to the sequence of these genes. However, definitive elucidation of homologies of osmoregulation genes must await sequencing of the Ps. maritimus genome to obtain the full set of aquaporin genes and GH-13 genes in this insect, and experimental validation of water transport and sucrase activity of the selected genes. 
Novel methods to control insect pests tend to be developed on species that are amenable to laboratory cultivation. In this respect, Ps. maritimus poses major logistical problems because its availability in the field is seasonal and, prior to the husbandry advances that made this study possible, it failed to thrive under insectary conditions. Nevertheless, insect material was always limiting for this study, and our experimental designs depended on prior knowledge gained of other phloem-feeding insects. In particular, we made use of the evidence from published studies that RNAi against $A Q P$ and SUC genes can function synergistically $[28,31]$, presumably because the dual RNAi reduces the capacity of each gene product to compensate for functional deficiencies in the other. These studies revealed that insects administered both ds $A Q P 1$ and dsSUC1 cannot compensate for the increased osmotic pressure in the gut caused by reduced transglucosidation (SUC1 function) by increased water cycling (AQP1 function), and vice versa. Further research conducted with larger numbers of insects will be required to establish the individual contributions of ds $A Q P 1$ and dsSUC1 and synergistic interactions between these treatments in RNAi against Ps. maritimus.

In our experiments, RNAi against the osmoregulation genes $A Q P 1$ and SUC1 yielded significantly increased mortality, relative to treatment $G$ control, only in conjunction with the nuclease gene NUC1, which we demonstrated to have enriched expression in the gut (Figure 2). These results are fully consistent with the accumulating evidence that gut nuclease activity is a major cause of poor RNAi efficiency in various insects [28,36,37,45-51]. The function of the nuclease of sternorrhynchan hemipterans has not been investigated, other than as an inhibitor of RNAi. It is not an essential enzyme, in the sense that RNAi against this gene does not increase insect mortality $([28,37,52]$ and this study), although reduced nymphal growth of dsNUC-treated pea aphids has been reported [37]. The natural substrate of insect gut nucleases may be DNA and RNA in disrupted insect cells sloughed off to the gut lumen during the natural process of gut epithelium turnover $[53,54]$, as well as nucleic acids in the phloem sap diet [55]. If the nucleotide products of gut nuclease activity are assimilated across the insect gut wall and used as substrates for de novo nucleic acid synthesis, the nuclease would have a nutritional role. However, our experiments cannot exclude the alternative explanation that dsNUC1 pretreatment activated a nonspecific RNAi response. Such responses have been reported in other insects, e.g., [56,57], but have not been investigated in mealybugs. Further research can investigate this possibility, for example by including dsGFP control treatments in the pretreatment phase of experiments.

From the applied perspective of insect pest control, the effects of RNAi on insect performance is the prime criterion of RNAi efficacy. The complementary index of reduced expression of the target gene is widely considered to offer validation of mechanism $[33,58]$. The reduced transcript abundance of $A Q P 1$ and SUC1 in the guts of insects fed on diets containing these dsRNAs (treatments $\mathrm{A}+\mathrm{S}$ and $\mathrm{N}+\mathrm{A}+\mathrm{S}$ in Table 1) supports this interpretation, but two aspects of the gene expression dataset (Figure 4) are inconsistent. First, we expected the expression knockdown of these target genes, relative to the dsGFP-containing diet (treatment $G$ ), to be greater in treatment $A+S$, with $d s A Q P 1$ and $d s S U C 1$ at double the concentration in treatment $\mathrm{N}+\mathrm{A}+\mathrm{S}$, but we obtained the opposite results. Second, the expression of $N U C 1$ is expected to be equivalent in treatments $\mathrm{N}+\mathrm{G}$ and $\mathrm{N}+\mathrm{A}+\mathrm{S}$, with administered $d s N U C 1$ at the same concentration. Instead, the expression of $d s N U C 1, \mathrm{ds} A Q P 1$ and dsSUC1 was reduced in treatment $\mathrm{N}+\mathrm{A}+\mathrm{S}$, with the highest mortality. We hypothesize that reduced gene expression was, at least partly, a consequence (not a cause) of suboptimal performance, specifically because the living insects feeding on dsRNA against osmoregulation genes were unhealthy and displaying reduced expression of certain genes with gut-specific function relative to house-keeping genes. This interpretation is consistent with reports of weak or variable correspondence between transcript abundance and insect performance [31,33,37,59]. Importantly, our results for NUC1 gene expression in dsNUC1-treated insects are very similar to published data for the nuclease gene in the sweet potato weevil Cylas puncticollis [60], where nuclease expression was decreased only when nuclease dsRNA was administered in conjunction with dsRNA against the target gene (specifically, Snf7). An important implication of this interpretation is that RNAi against the osmoregulation genes of 
Ps. maritimus would likely yield greater mortality effects over a longer time course than the three days adopted in this study. Such analysis, however, will require the development of in planta delivery of RNAi because the artificial diet system used here is unsuitable for extended experiments.

A further potential limitation of our expression analysis was that a single gene, $\beta$-tubulin, was used for normalization in the qPCR analyses. Although other candidate housekeeping genes were considered, none, other than $\beta$-tubulin, yielded a reliable sequence with degenerate primers. This is a consequence of the lack of genomic data for Ps. maritimus, and other expression analyses of mealybug species have, similarly, used a single gene for normalization $[16,19]$. Although the precision and accuracy of expression analyses are improved by the use of two or more housekeeping genes, two considerations indicate that our use of $\beta$-tubulin did not introduce substantial bias. First, $\beta$-tubulin is a reliable housekeeping gene for expression analysis in related hemipteran insects (whiteflies and aphids) [28,37]. Second, the elevated expression of the genes of interest for this study in the gut relative to the whole body (Figure 2) could not be attributed to reduced $\beta$-tubulin expression in the gut because expression of a further gene, SUC4, was not elevated in the gut (Arora, unpub. data). As additional molecular data become available for Ps. maritimus, it will become feasible to employ multiple reference genes for expression analysis.

A final issue raised by this study relates to the specificity of the RNAi treatments to the pest species. The predicted non-target potential of the dsRNA constructs used in this study against insects other than Ps. maritimus was limited to other mealybugs and did not extend to aphids, members of the sister group to Coccoidea. In the context of the grapevine system, the activity of single dsRNA constructs against all grape-infesting mealybugs is an efficient route for crop protection. These results should, however, be interpreted with great caution. The weak correspondence between gene expression levels and insect performance (see previous paragraph) is most readily explained by a contribution of perturbed translation of the target gene to the RNAi effect [61]. Importantly, lower sequence identity between the siRNA and target transcript is required for translational suppression than for the canonical RNAi mechanism of transcript degradation [62,63], with the implication that the dsRNA may have lower species specificity than predicted. Applying the principles of studies on the effects of RNAi triggers to nontarget insect species $[9,64]$, a priority for future research is to determine empirically the efficacy of dsRNAs designed for Ps. maritimus against other grapevine mealybug pest species and other insects in the grapevine cultivation system.

\section{Conclusions}

In conclusion, this study provides the first demonstration of the feasibility of an RNAi-based strategy targeting insect osmoregulatory function for the control of the grapevine pest, Ps. maritimus. It offers the basis for targeted in planta analysis of RNAi against osmoregulation genes and, more generally, illustrates the opportunity to develop RNAi against insect pests that are traditionally perceived as intractable because they lack genomic resources and routine laboratory maintenance protocols.

Supplementary Materials: The following are available online at http://www.mdpi.com/2075-4450/11/11/739/s1, Figure S1. Rooted phylogenetic trees were constructed depicting relationship between AQP proteins using (A) Bayesian method (bootstrap values are shown on the branches) and (B) maximum likelihood method [the numbers on the branches are Shimodaira-Hasegawa approximate likelihood-ratio test (SH-aLRT) support (\%)/ultrafast bootstrap support (\%)]. Bacterial aquaporin proteins were used as an outgroup. Abbreviations: AQPZ, aquaporin Z; BIB, neurogenic protein big brain; DRIP, Drosophila integral protein family; EGLP, entomoglyceroporin; PRIP, Pyrocoelia rufa integral protein family. (C) Alignment of $A Q P-1$ gene of Acyrthosiphon pisum (accession number ACYPI006387), Pseudococcus. maritimus (accession number MT187985) and Planococcus ficus (accession number MT192030). Ps. maritimus dsRNA primer binding sites are highlighted yellow and qPCR primer binding sites are highlighted blue. Phylogenetic information was used to design degenerate primers for $A Q P 1$. The aquaporin sequences in Figure S1A,B are: Insects Sternorrhyncha (Hemiptera): aphids-Aphis craccivora [GAJW01004051.1], A. craccivora [KAF0764833.1], A. curvipes [GAJV01000737.1], A. glycines [KAE9531406.1], A. glycines [KAE9532649.1], A. glycines [KAE9534820.1], A. gossypii [AQZ36557.1], A. gossypii [XP027843520.1], A. gossypii[ XP027848076.1], A. pisum [ACYPI006387, A. pisum [ACYPI009194-PA], A. pisum [ACYPI010017], Cinara cedri [VVC32829.1], C. cedri [VVC43224.1], Diuraphis noxia [XP015366196.1], D. noxia [XP015367453.1], Myzus ascalonicus [FO032683.1], 
M. ascalonicus [GAAF01000345.1], Macrosiphum euphorbiae [GAOM01002305.1], Myzus persicae [XP022161341.1], M. persicae [XP022172799.1], M. persicae [XP022173314.1], Melanaphis sacchari [XP025197871.1], M. sacchari [XP025198278.1], M. sacchari [XP025200968.1], Rhopalosiphum maidis [XP026806330.1], R. maidis [XP026808959.1], R. maidis [XP026812299.1], Rhopalosiphum padi [AJL33751.1], Sipha flava [XP025405491.1], S. flava [XP025406216.1], S. flava [XP025409656.1]; whiteflies-Bemisia tabaci [APA28759.1], B. tabaci [APA28760.1], B. tabaci [APA28761.1], B. tabaci [APA28762.1], B. tabaci [XP018906592.1], B. tabaci [XP018908128.1], B. tabaci [XP018913501.1]; mealybugs-Planococcus citri [AQP-1, MT187985], Pl. citri [AQP-2], Pl. citri [AQP-3], Pl. citri [AQP-4], Pl. citri [AQP-5], Pl. citri [AQP-6], Pl. citri [AQP-7], Pl. citri [AQP-8], Pl. ficus [AQP-1, MT192030], Ps maritimus [AQP-1], Phenacoccus solenopsis [AYN64406.1]. psyllids-Bactericera cockerelli [AHB86600.1], B. cockerelli [AHB86601.2], B. cockerelli [AHB86602.2], B. cockerelli [AHB86603.1], Diaphorina citri [GACJ01000325.1], D. citri [GACJ01023397.1], D. citri [XP008484232.1], D. citri [XP008487274.1]; Auchenorrhyncha (Hemiptera): leafhoppers-Cicadella viridis [Q23808.1], Homalodisca vitripennis [DN195967.1]; planthoppers-Laodelphax striatellus [RZF36961.1], Nilaparvata lugens [XP022185065.1], N. lugens [XP022198592.1], N. lugens [XP022199860.1], N. lugens [XP022205785.1]. Heteroptera (Hemiptera):true bugs-Apolygus lucorum [KAE9438756.1], Lygus hesperus [AHI85743.1], L. hesperus [AHI85746.1], L. hesperus [AHI85749.1], L. hesperus [AHI85750.1], Cimex lectularius [AMZ04825.1], C. lectularius [AMZ04828.1], C. lectularius [AMZ04829.1], C. lectularius [AMZ04830.1], Clavigralla tomentosicollisgi [GAJX01000223.1], C. tomentosicollisgi [GAJX01005354.1], Halyomorpha halys [XP024216106.1]; Rhodnius prolixus [RPRC002014-PA], R. prolixus [RPRC002387-PA], R. prolixus [RPRC003319-PA], R. prolixus [RPRC003382-PA], R. prolixus [RPRC008707-PA], R. prolixus [RPRC011100-PA]; Riptortus pedestris [BAN21211.1]. Diptera: fruit flies-Drosophila melanogaster [NP611810.1, EGLP1], D. melanogaster [AAF58642.1.PRIP], D. melanogaster [AAM68740.2, DRIP], D. melanogaster [NP476837.1, BIB], D. melanogaster [NP611811.3, EGLP2], D. melanogaster [NP611812.2, EGLP3], D. melanogaster [NP611813.1, EGLP4]. Bacteria-Bacillus subtilis [CUB53001.1-AQPZ], B. subtilis [WP015383197.1-Aquaglyceroporin], Enterococcus faecalis [STP66220.1-Aquaglyceroporin], E. faecalis [WP025188124.1-AQPZ], Streptococcus pneumoniae [CJR57869.1-Aquaglyceroporin], and S. pneumoniae [VTQ31887.1-AQPZ]. Enterobacter cloacae [WP129996330.1-AQPZ], E. cloacae [VAV80647.1-Aquaglyceroporin], Escherichia. Coli [AAC43518.1-AQPZ], E. coli [SYX52609.1-Aquaglyceroporin], Pseudomonas aeruginosa [SZD40238.1-Aquaglyceroporin], P. aeruginosa [WP029610146.1-AQPZ]. A. pisum and R. prolixus sequences were retrieved from aphidbase (https://bipaa.genouest.org/sp/acyrthosiphon_pisum/) and vectorbase (https: //www.vectorbase.org/organisms/rhodnius-prolixus), respectively. The remaining sequences were downloaded from NCBI (https://blast.ncbi.nlm.nih.gov/Blast.cgi). Figure S2. Rooted phylogenetic trees were constructed depicting the relationship between sucrase proteins using (A) Bayesian method (bootstrap values are shown on the branches) and (B) maximum likelihood method (the numbers on the branches are SH-aLRT support (\%)/ultrafast bootstrap support (\%). Drosophila melanogaster sucrase proteins were used as an outgroup. (C) Alignment of SUC-1 gene of Acyrthosiphon pisum (accession number ACYPI000002), Pseudococcus maritimus (accession number MT187986) and Planococcus ficus (accession number MT192031). Ps. maritimus SUC1-dsRNA primer binding sites are highlighted blue and GPCR primer binding sites are highlighted yellow. Phylogenetic information was used to design degenerate primers for SUC1. The sucrase sequences used in Figure S2A,B are: Insects Sternorrhyncha (Hemiptera): aphids-Aphis craccivora [KAF0746146.1], A. craccivora [KAF0766705.1], A craccivora [KAF0767588.1], A. glycines [AG007859-PA], A. glycines [AG007860-PA], A. glycines [AG012057-PA], A. glycines [AG012058-PA], A. glycines [AG012059-PA], A. glycines [AG015450-PA], A. glycines [AG016935-PA], A. glycines [AG018074-PA], A. glycines [AG018961-PA], A. gossypii [XP_027847697.1], A. gossypii [XP_027847702.1], A. pisum [ACYPI000002-PA], A. pisum [ACYPI000768-PA], A. pisum [ACYPI002659-PA], A. pisum [ACYPI007753-PA], A. pisum [ACYPI008964-PA], A. pisum [XP_001952163.2], A. pisum [XP_003246887.1], A. pisum [XP_016659005.1], Cinara cedri [VVC30056.1], C. cedri [VVC30062.1], C. cedri [VVC30063.1], Diuraphis noxia [XP_015374664.1], D. noxia [XP_015375687.1], D. noxia [XP_015375756.1], Myzus persicae [XP_022164993.1], M. persicae [XP_022171053.1], M. persicae [XP_022171472.1], M. persicae [XP_022171483.1], M. persicae [XP_022171586.1], M. persicae [XP_022171691.1], M. persicae [XP_022171737.1], M. persicae [XP_022171816.1], Melanaphis sacchari [XP_025200270.1], M. sacchari [XP_025200431.1], M. sacchari [XP_025201971.1], Rhopalosiphum maidis [XP_026808057.1], R. maidis [XP_026808060.1], R. maidis [XP_026808063.1], R. maidis [XP_026808310.1], R. maidis [XP_026811817.1], R. maidis [XP_026811838.1], R. maidis [XP_026814773.1], R. maidis [XP_026821988.1], Sipha flava [XP_025406535.1], S. flava [XP_025411858.1], S. flava [XP_025411859.1], S. flava [XP_025411872.1], S. flava [XP_025411875.1], S. flava [XP_025411876.1], S. flava [XP_025411886.1], and S. flava [XP_025411887.1]; whiteflies-Bemisia tabaci [XP_018895643.1], B. tabaci [XP_018895757.1], B. tabaci [XP_018895821.1], B. tabaci [XP_018896838.1], B. tabaci [XP_018907630.1], B. tabaci [XP_018907649.1], B. tabaci [XP_018907799.1], B. tabaci [XP_018907832.1], B. tabaci [XP_018908637.1], B. tabaci [XP_018909206.1], B. tabaci [XP_018909322.1], B. tabaci [XP_018910471.1], B. tabaci [XP_018910472.1], B. tabaci [XP_018914092.1], B. tabaci [XP_018916040.1], B. tabaci [XP_018916662.1], B. tabaci [XP_018917258.1], B. tabaci [XP_018917350.1], B. tabaci [XP_018917351.1], B. tabaci [XP_018917500.1], B. tabaci [XP_018917587.1]; mealybugs-Planococcus citri [SUC1], Pl. citri [SUC4], Pl. citri [SUC5], Pl. ficus [SUC1, MT192031], Ps. maritimus [SUC1, MT187986], Ps. maritimus [SUC4, MT187987]. Auchenorrhyncha (Hemiptera): planthopper-Laodelphax striatellus [RZF35393.1], L. striatellus [RZF38899.1], Nilaparvata lugens [XP_022191426.1], N. lugens [XP_022191429.1], N. lugens [XP_022191432.1], N. lugens [XP_022191433.1], N. lugens [XP_022200264.1]. Diptera: fruit flies-Drosophila melanogaster [AAY55205.1], D. melanogaster [NP_001188791.2], D. melanogaster [NP_001286198.1], D. melanogaster [NP_476625.2], D. melanogaster [NP_476627.3], D. melanogaster [NP_476628.2], D. melanogaster [NP_609522.1], D. melanogaster [NP_610381.1], D. melanogaster [NP_610382.2], D. melanogaster [NP_610384.1], D. melanogaster [NP_724679.2]. A. pisum and R. prolixus sequences were retrieved from aphidbase (https://bipaa.genouest.org/sp/acyrthosiphon_pisum/) and vectorbase (https://www.vectorbase.org/organisms/rhodnius-prolixus), respectively. The remaining sequences 
were downloaded from NCBI (https://blast.ncbi.nlm.nih.gov/Blast.cgi). Figure S3. Rooted phylogenetic trees were constructed depicting relationship between DNA/RNA non-specific nuclease using (A) Bayesian method (bootstrap values are shown on the branches) and (B) maximum likelihood method (the numbers on the branches are SH-aLRT support (\%)/ultrafast bootstrap support (\%). Endonuclease G proteins from different species were used as an outgroup. (C) Alignment of NUC1 gene of Acyrthosiphon pisum (accession number ACYPI008471), Pseudococcus. maritimus (accession number MT187988) and Planococcus ficus (accession number MT192032). Ps. maritimus NUC1-dsRNA primer binding sites are highlighted blue and qPCR primer binding sites are highlighted yellow. Phylogenetic information was used to design degenerate primers for NUC1. The sucrase sequences used in Figure S3A,B are: Insects Sternorrhyncha (Hemiptera): aphids-A. pisum [ACYPI008471], Aphis craccivora [KAF0769485.1], A. craccivora [KAF0771557.1], A. glycines [KAE9531558.1], A. gossypii [XP_027843039.1], Cinara cedri [VVC35734.1], Diuraphis noxia [XP_015375167.1], Melanaphis sacchari [XP_025194442.1], Myzus persicae [XP_022183034.1], Rhopalosiphum maidis [XP_026811795.1]; Sipha flava [XP_025416859.1]; whiteflies-Bemicia. Tabaci [AQU43106.1], B. tabaci [AQU43107.1]; mealybugs-Planococcus citri [NUC1], Pl. ficus [NUC1, MT192032], Ps. maritimus [NUC1, MT187988]. Auchenorrhyncha (Hemiptera): Psyllids-Diaphorina citri [XP_008483858.1], D. citri [XP_015375305.1]; the planthopper-Laodelphax striatellus [QCB20006.1], L. striatellus [RZF42780.1], Nilaparvata lugens [XP_022200679.1]. Hymenoptera: honey beesApis mellifera [XP_624107.3]. Diptera: fruit flies-Drosophila melanogaster [NP_649076.1], D. melanogaster [NP_649078.1]. Coleoptera: beetles-Tribolium castaneum [XP_970494.1], T. castaneum [XP_973587.1]. Heteroptera: bugs-Rhodnius prolixus [RPRC015371]. Lepidoptera: moths-Bombyx mori [AK383943.1], B. mori [NP_001091744.1], B. mori [XP_004922835.1], B. mori [XP_004925361.1]. Orthoptera: locusts- Schistocerca gregaria [ÄHN55088.1], S. gregaria [AHN55089.1], S. gregaria [AHN55090.1], S. gregaria [AHN55091.1]. Nematoda: nematodesBrugia malayi [XP_001892352.1], Caenorhabditis elegans [NP_491371.1], Trichinella spiralis [XP_003375679.1]. Mammalia: cow-Bos Taurus [CAA51320.1]; humans-Homo sapiens [AAX29001.1]; mouse- $\overline{\text { Mus }}$ musculus [NP_031957.1]. Crustacea: crab-Chionoecetes opilio [BAI79321.2], amphipod-Gammarus_sp. [ABI18973.1], shrimp—Pandalus borealis [CBG22733.1], Penaeus monodon [ABF69938.1]. Bacteria-Salmonella enterica [AAL91099.1], Serratia marcescens [AAA26560.1]. Virus-white spot syndrome virus (WSSV) [AAW88443.1]. A. pisum and R. prolixus sequences were retrieved from aphidbase (https://bipaa.genouest.org/sp/acyrthosiphon_pisum/) and vectorbase (https://www.vectorbase.org/organisms/rhodnius-prolixus), respectively. The remaining sequences were downloaded from NCBI (https://blast.ncbi.nlm.nih.gov/Blast.cgi). Figure S4. Alignment of $\beta t u b$ gene of Acyrthosiphon pisum (accession number ACYPI001007) and Pseudococcus. maritimus (accession number MT187989). Ps. maritimus $\beta t u b$ qPCR primer binding sites are highlighted in yellow. Figure S5. The dsRNA target sequence alignment of Pseudococcus maritimus genes with the sequences of homologous genes from other species with predicted potential of non-target activity (A) Ps maritimus ds $A Q P 1$ (250 bp) with Planococcus citri AQP1; (B) Ps. maritimus ds $A Q P 1$ with Pl. ficus AQP1; (C) Ps. maritimus dsNUC1 (250 bp) with Pl. ficus NUC1; (D) Ps. maritimus dsNUC1 with Pl. ficus NUC1. Perfect sequence matches that equal or exceed 21 bp are highlighted in yellow. Text S1. Phylogenetic analysis of candidate genes. Table S1. Primer sequences. Table S2. PCR amplification conditions to amplify gene regions. Table S3. Statistical analysis of the effect of RNAi treatments on P. maritimus survival. Table S4 Statistical analysis of the effect of RNAi treatments on the expression of P. maritimus genes. Dataset S1. Mortality of Pseudococcus maritimus in RNAi experiments.

Author Contributions: A.E.D., G.L. and M.F. conceived the research. A.K.A. and A.E.D. designed the experiment. K.S.W. and S.H. identified the optimal conditions and maintained the insect colony. A.K.A., K.S.W. and S.H. developed the feeding assays. A.K.A. performed the feeding assays. A.K.A. and N.C. sequenced the genes and ran qPCR. A.K.A. performed the statistical analysis. A.K.A. and A.E.D. drafted the manuscript. A.E.D., G.L. and M.F. acquired the funding. All the authors reviewed and edited the manuscript. All authors have read and agreed to the published version of the manuscript.

Funding: This research was funded by California Department of Food and Agriculture grants 17-0416-000-SA and 19-0263-000-SA.

Acknowledgments: We thank Danielle E. Preston (Cornell University, Ithaca) who assisted with Ps. maritimus gut dissections, John G. McMullen II (Cornell University, Ithaca) for advice with statistics, Kent Daane (UC, Berkeley) who supplied frozen Pl. ficus specimens and X. Jiang (Northwest University, Xi'an, China) who provided Pl. citri $\mathrm{AQP}$ and SUC sequences.

Conflicts of Interest: The authors declare no conflict of interest.

\section{References}

1. Daane, K.M.; Almeida, R.P.P.; Bell, V.A.; Walker, J.T.S.; Botton, M.; Fallahzadeh, M.; Mani, M.; Miano, J.L.; Sforza, R.; Walton, V.M.; et al. Biology and Management of Mealybugs in Vineyards; Bostanian, N.J., Isaacs, R., Vincent, C., Eds.; Springer: Dordrecht, The Netherlands, 2012.

2. Atallah, S.S.; Gomez, M.I.; Fuchsberger, C.; Martinson, T.E. Economic impact of grapevine leafroll disease on Vitis vinifera cv. Cabernet franc in Finger Lakes vineyards of New York. Am. J. Enol. Viticult. 2012, 63, 73-79. [CrossRef] 
3. Cooper, M.L.; Daugherty, M.P.; Jeske, D.R.; Almeida, R.P.P.; Daane, K.M. Incidence of grapevine leafroll disease: Effects of grape mealybug (Pseudococcus maritimus) abundance and pathogen supply. J. Econ. Entomol. 2018, 111, 1542-1550. [CrossRef] [PubMed]

4. Wallingford, A.K.; Fuchs, M.F.; Martinson, T.; Hesler, S.; Loeb, G.M. Slowing the Spread of Grapevine Leafroll-Associated Viruses in Commercial Vineyards With Insecticide Control of the Vector, Pseudococcus maritimus (Hemiptera: Pseudococcidae). J. Insect. Sci. 2015, 15, 112. [CrossRef]

5. Weigle, T.H.; Muza, A.J. (Eds.) New York and Pennsylvania Pest Management Guidelines for Grapes; A Cornell and Penn State Cooperative Extension Publication: Ithaca, NY, USA, 2020.

6. Cooper, A.M.; Silver, K.; Zhang, J.; Park, Y.; Zhu, K.Y. Molecular mechanisms influencing efficiency of RNA interference in insects. Pest Manag. Sci. 2019, 75, 18-28. [CrossRef] [PubMed]

7. Vogel, E.; Santos, D.; Mingels, L.; Verdonckt, T.W.; Broeck, J.V. RNA Interference in Insects: Protecting Beneficials and Controlling Pests. Front. Physiol. 2019, 10, 1912. [CrossRef] [PubMed]

8. Whyard, S.; Singh, A.D.; Wong, S. Ingested double-stranded RNAs can act as species-specific insecticides. Insect Biochem. Mol. Biol. 2009, 39, 824-832. [CrossRef]

9. Zhu, K.Y.; Palli, S.R. Mechanisms, Applications, and Challenges of Insect RNA Interference. Annu. Rev. Entomol. 2020, 65, 293-311. [CrossRef]

10. Fire, A.; Xu, S.; Montgomery, M.K.; Kostas, S.A.; Driver, S.E.; Mello, C.C. Potent and specific genetic interference by double-stranded RNA in Caenorhabditis elegans. Nature 1998, 391, 806-811. [CrossRef]

11. Wilson, R.C.; Doudna, J.A. Molecular mechanisms of RNA interference. Annu. Rev. Biophys. 2013, 42, 217-239. [CrossRef] [PubMed]

12. Cagliari, D.; Dias, N.P.; Galdeano, D.M.; Dos Santos, E.A.; Smagghe, G.; Zotti, M.J. Management of Pest Insects and Plant Diseases by Non-Transformative RNAi. Front. Plant Sci. 2019, 10, 1319. [CrossRef] [PubMed]

13. Douglas, A.E. Strategies for Enhanced Crop Resistance to Insect Pests. Annu. Rev. Plant Biol. 2018, 69, 637-660. [CrossRef] [PubMed]

14. Zotti, M.; Dos Santos, E.A.; Cagliari, D.; Christiaens, O.; Taning, C.N.T.; Smagghe, G. RNA interference technology in crop protection against arthropod pests, pathogens and nematodes. Pest Manag. Sci. 2018, 74, 1239-1250. [PubMed]

15. Husnik, F.; Nikoh, N.; Koga, R.; Ross, L.; Duncan, R.P.; Fujie, M.; Tanaka, M.; Satoh, N.; Bachtrog, D.; Wilson, A.C.; et al. Horizontal gene transfer from diverse bacteria to an insect genome enables a tripartite nested mealybug symbiosis. Cell 2013, 153, 1567-1578. [CrossRef] [PubMed]

16. Singh, S.; Gupta, M.; Pandher, S.; Kaur, G.; Goel, N.; Rathore, P. Using de novo transcriptome assembly and analysis to study RNAi in Phenacoccus solenopsis Tinsley (Hemiptera: Pseudococcidae). Sci. Rep. 2019, 9, 13710. [PubMed]

17. Khan, A.M.; Ashfaq, M.; Khan, A.A.; Naseem, M.T.; Mansoor, S. Evaluation of potential RNA-interferencetarget genes to control cotton mealybug, Phenacoccus solenopsis (Hemiptera: Pseudococcuidae). Insect Sci. 2018, 25, 778-786.

18. Khan, A.M.; Ashfaq, M.; Kiss, Z.; Khan, A.A.; Mansoor, S.; Falk, B.W. Use of recombinant tobacco mosaic virus to achieve RNA interference in plants against the citrus mealybug, Planococcus citri (Hemiptera: Pseudococcidae). PLOS ONE 2013, 8, e73657.

19. Omar, M.A.A.; Ao, Y.; Li, M.; He, K.; Xu, L.; Tong, H.; Jiang, M.; Li, F. The functional difference of eight chitinase genes between male and female of the cotton mealybug, Phenacoccus solenopsis. Insect Mol. Biol. 2019, 28, 550-567.

20. Mathew, L.G.; Campbell, E.M.; Yool, A.J.; Fabrick, J.A. Identification and characterization of functional aquaporin water channel protein from alimentary tract of whitefly, Bemisia tabaci. Insect Biochem. Mol. Biol. 2011, 41, 178-190. [CrossRef]

21. Price, D.R.; Karley, A.J.; Ashford, D.A.; Isaacs, H.V.; Pownall, M.E.; Wilkinson, H.S.; Gatehouse, J.A.; Douglas, A.E. Molecular characterisation of a candidate gut sucrase in the pea aphid, Acyrthosiphon pisum. Insect Biochem. Mol. Biol. 2007, 37, 307-317.

22. Shakesby, A.J.; Wallace, I.S.; Isaacs, H.V.; Pritchard, J.; Roberts, D.M.; Douglas, A.E. A water-specific aquaporin involved in aphid osmoregulation. Insect Biochem. Mol. Biol. 2009, 39, 1-10. [CrossRef]

23. Ashford, D.A.; Smith, W.A.; Douglas, A.E. Living on a high sugar diet: The fate of sucrose ingested by a phloem-feeding insect, the pea aphid Acyrthosiphon pisum. J. Insect Physiol. 2000, 46, 335-341. [CrossRef] 
24. Karley, A.J.; Ashford, D.A.; Minto, L.M.; Pritchard, J.; Douglas, A.E. The significance of gut sucrase activity for osmoregulation in the pea aphid, Acyrthosiphon pisum. J. Insect Physiol. 2005, 51, 1313-1319. [CrossRef] [PubMed]

25. Wilkinson, T.; Ashford, D.; Pritchard, J.; Douglas, A. Honeydew sugars and osmoregulation in the pea aphid Acyrthosiphon pisum. J. Exp. Biol. 1997, 200, 2137-2143. [PubMed]

26. Douglas, A.E. Nutritional physiology of aphids. Adv. Insect Physiol. 2003, 31, 73-140.

27. Van Ekert, E.; Chauvigne, F.; Finn, R.N.; Mathew, L.G.; Hull, J.J.; Cerda, J.; Fabrick, J.A. Molecular and functional characterization of Bemisia tabaci aquaporins reveals the water channel diversity of hemipteran insects. Insect Biochem. Mol. Biol. 2016, 77, 39-51. [CrossRef] [PubMed]

28. Luo, Y.; Chen, Q.; Luan, J.; Chung, S.H.; Van Eck, J.; Turgeon, R.; Douglas, A.E. Towards an understanding of the molecular basis of effective RNAi against a global insect pest, the whitefly Bemisia tabaci. Insect Biochem. Mol. Biol. 2017, 88, 21-29. [CrossRef] [PubMed]

29. Raza, A.; Malik, H.J.; Shafiq, M.; Amin, I.; Scheffler, J.A.; Scheffler, B.E.; Mansoor, S. RNA Interference based Approach to Down Regulate Osmoregulators of Whitefly (Bemisia tabaci): Potential Technology for the Control of Whitefly. PLoS ONE 2016, 11, e0153883. [CrossRef] [PubMed]

30. Santos-Ortega, Y.; Killiny, N. Silencing of sucrose hydrolase causes nymph mortality and disturbs adult osmotic homeostasis in Diaphorina citri (Hemiptera: Liviidae). Insect Biochem. Mol. Biol. 2018, 101, 131-143. [CrossRef]

31. Tzin, V.; Yang, X.; Jing, X.; Zhang, K.; Jander, G.; Douglas, A.E. RNA interference against gut osmoregulatory genes in phloem-feeding insects. J. Insect Physiol. 2015, 79, 105-112. [CrossRef]

32. Jing, X.; White, T.A.; Luan, J.; Jiao, C.; Fei, Z.; Douglas, A.E. Evolutionary conservation of candidate osmoregulation genes in plant phloem sap-feeding insects. Insect Mol. Biol. 2016, 25, 251-258. [CrossRef]

33. Scott, J.G.; Michel, K.; Bartholomay, L.C.; Siegfried, B.D.; Hunter, W.B.; Smagghe, G.; Zhu, K.Y.; Douglas, A.E. Towards the elements of successful insect RNAi. J. Insect Physiol. 2013, 59, 1212-1221. [CrossRef] [PubMed]

34. Yu, X.D.; Liu, Z.C.; Huang, S.L.; Chen, Z.Q.; Sun, Y.W.; Duan, P.F.; Ma, Y.Z.; Xia, L.Q. RNAi-mediated plant protection against aphids. Pest Manag. Sci. 2016, 72, 1090-1098. [CrossRef] [PubMed]

35. Christiaens, O.; Whyard, S.; Vélez, A.M.; Smagghe, G. Double-stranded RNA technology to control insect pests: Current status and challenges. Front. Plant Sci. 2020, 11, 451. [CrossRef] [PubMed]

36. Christiaens, O.; Swevers, L.; Smagghe, G. DsRNA degradation in the pea aphid (Acyrthosiphon pisum) associated with lack of response in RNAi feeding and injection assay. Peptides 2014, 53, 307-314. [CrossRef] [PubMed]

37. Chung, S.H.; Jing, X.; Luo, Y.; Douglas, A.E. Targeting symbiosis-related insect genes by RNAi in the pea aphid-Buchnera symbiosis. Insect Biochem. Mol. Biol. 2018, 95, 55-63. [CrossRef] [PubMed]

38. Cousins, P. Tiny grape could do big things. Agric. Res. 2007, 55, 23.

39. Edgar, R.C. MUSCLE: Multiple sequence alignment with high accuracy and high throughput. Nucleic Acids Res. 2004, 32, 1792-1797. [CrossRef]

40. Livak, K.J.; Schmittgen, T.D. Analysis of relative gene expression data using real-time quantitative PCR and the 2(-Delta Delta C(T)) Method. Methods 2001, 25, 402-408. [CrossRef]

41. Douglas, A.E.; Minto, L.B.; Wilkinson, T.L. Quantifying nutrient production by the microbial symbionts in an aphid. J. Exp. Biol. 2001, 204, 349-358.

42. Luck, S.; Kreszies, T.; Strickert, M.; Schweizer, P.; Kuhlmann, M.; Douchkov, D. siRNA-Finder (si-Fi) Software for RNAi-Target Design and Off-Target Prediction. Front. Plant Sci. 2019, 10, 1023. [CrossRef]

43. R Core Team. R: A Language and Environment for Statistical Computing; R Foundation for Statistical Computing: Vienna, Austria, 2015; Available online: https://www.R-project.org/ (accessed on 7 September 2019).

44. Bates, D.; Machler, M.; Bolker, B.; Walker, S. Fitting linear mixed-effects models using lme-4. J. Stat. Softw. 2015, 67, 1-48. [CrossRef]

45. Peng, Y.; Wang, K.; Chen, J.; Wang, J.; Zhang, H.; Ze, L.; Zhu, G.; Zhao, C.; Xiao, H.; Han, Z. Identification of a double-stranded RNA-degrading nuclease influencing both ingestion and injection RNA interference efficiency in the red flour beetle Tribolium castaneum. Insect Biochem. Mol. Biol. 2020, 125, 1-10. [CrossRef] [PubMed]

46. Peng, Y.; Wang, K.; Fu, W.; Sheng, C.; Han, Z. Biochemical Comparison of dsRNA Degrading Nucleases in Four Different Insects. Front. Physiol. 2018, 9, 624. [CrossRef] 
47. Song, H.; Zhang, J.; Li, D.; Cooper, A.M.W.; Silver, K.; Li, T.; Liu, X.; Ma, E.; Zhu, K.Y.; Zhang, J. A double-stranded RNA degrading enzyme reduces the efficiency of oral RNA interference in migratory locust. Insect Biochem. Mol. Biol. 2017, 86, 68-80. [CrossRef]

48. Spit, J.; Philips, A.; Wynant, N.; Santos, D.; Plaetinck, G.; Vanden Broeck, J. Knockdown of nuclease activity in the gut enhances RNAi efficiency in the Colorado potato beetle, Leptinotarsa decemlineata, but not in the desert locust, Schistocerca gregaria. Insect Biochem. Mol. Biol. 2017, 81, 103-116. [CrossRef]

49. Wang, K.; Peng, Y.; Pu, J.; Fu, W.; Wang, J.; Han, Z. Variation in RNAi efficacy among insect species is attributable to dsRNA degradation in vivo. Insect Biochem. Mol. Biol. 2016, 77, 1-9. [CrossRef]

50. Wynant, N.; Santos, D.; Verdonck, R.; Spit, J.; Van Wielendaele, P.; Vanden Broeck, J. Identification, functional characterization and phylogenetic analysis of double stranded RNA degrading enzymes present in the gut of the desert locust, Schistocerca gregaria. Insect Biochem. Mol. Biol. 2014, 46, 1-8. [CrossRef] [PubMed]

51. Tayler, A.; Heschuk, D.; Giesbrecht, D.; Park, J.Y.; Whyard, S. Efficiency of RNA interference is improved by knockdown of dsRNA nucleases in tephritid fruit flies. Open Biol. 2019, 9, 190198. [CrossRef]

52. Chung, S.H.; Parker, B.J.; Blow, F.; Brisson, J.A.; Douglas, A.E. Host and symbiont genetic determinants of nutritional phenotype in a natural population of the pea aphid. Mol. Ecol. 2020, 29, 848-858. [CrossRef]

53. Huang, J.H.; Jing, X.; Douglas, A.E. The multi-tasking gut epithelium of insects. Insect Biochem. Mol. Biol. 2015, 67, 15-20. [CrossRef]

54. Ohlstein, B.; Spradling, A. The adult Drosophila posterior midgut is maintained by pluripotent stem cells. Nature 2006, 439, 470-474. [CrossRef] [PubMed]

55. Kehr, J.; Kragler, F. Long distance RNA movement. New Phytol. 2018, 218, 29-40. [CrossRef] [PubMed]

56. Flenniken, M.L.; Andino, R. Non-Specific dsRNA-mediated antiviral response in the honey bee. PLoS ONE 2013, 8, e77263. [CrossRef] [PubMed]

57. Nunes, F.M.F.; Aleixo, A.C.; Barchuk, A.R.; Bomtorin, A.D.; Grozinger, C.M.; Simões, Z.L.P. Non-target effects of green fluorescent protein (GFP)-derived double-stranded RNA (dsRNA-GFP) used in honey bee RNA interference (RNAi) assays. Insects 2013, 4, 90-103. [CrossRef]

58. Terenius, O.; Papanicolaou, A.; Garbutt, J.S.; Eleftherianos, I.; Huvenne, H.; Kanginakudru, S.; Albrechtsen, M.; An, C.; Aymeric, J.L.; Barthel, A.; et al. RNA interference in Lepidoptera: An overview of successful and unsuccessful studies and implications for experimental design. J. Insect Physiol. 2011, 57, 231-245. [CrossRef]

59. Wuriyanghan, H.; Rosa, C.; Falk, B.W. Oral delivery of double-stranded RNAs and siRNAs induces RNAi effects in the potato/tomato psyllid, Bactericerca cockerelli. PLoS ONE 2011, 6, e27736. [CrossRef]

60. Prentice, K.; Smagghe, G.; Gheysen, G.; Christiaens, O. Nuclease activity decreases the RNAi response in the sweetpotato weevil Cylas puncticollis. Insect Biochem. Mol. Biol. 2019, 110, 80-89. [CrossRef]

61. Fellmann, C.; Lowe, S.W. Stable RNA interference rules for silencing. Nat. Cell. Biol. 2014, 16, 10-18. [CrossRef]

62. Doench, J.G.; Petersen, C.P.; Sharp, P. A siRNAs can function as miRNAs. Genes Dev. 2003, 17, 438-442. [CrossRef]

63. Zeng, Y.; Yi, R.; Cullen, B.R. MicroRNAs and small interfering RNAs can inhibit mRNA expression by similar mechanisms. Proc. Natl. Acad. Sci. USA 2003, 100, 9779-9784. [CrossRef]

64. Roberts, A.F.; Devos, Y.; Lemgo, G.N.; Zhou, X. Biosafety research for non-target organism risk assessment of RNAi-based GE plants. Front. Plant Sci. 2015, 6, 958.

Publisher's Note: MDPI stays neutral with regard to jurisdictional claims in published maps and institutional affiliations.

(C) 2020 by the authors. Licensee MDPI, Basel, Switzerland. This article is an open access article distributed under the terms and conditions of the Creative Commons Attribution (CC BY) license (http://creativecommons.org/licenses/by/4.0/). 